\begin{tabular}{|c|c|}
\hline & $\begin{array}{l}\text { International Journal of Trend in Scientific } \\
\text { Research and Development (IJTSRD) }\end{array}$ \\
\hline 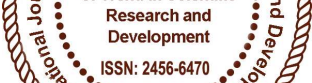 & International Open Access Journal \\
\hline 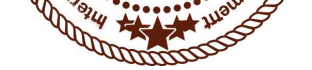 & ISSN No: 2456 - 6470 | www.ijtsrd.com | Volume - 2 | Issue - 2 \\
\hline
\end{tabular}

\title{
Pregnancy Outcomes and Risk Factors among Adolescents in Buea Health District, Southwest Region, Cameroon: A Comparative Study
}

\author{
Marcelus U. Ajonina \\ Meridian Global Education and Research \\ Foundation, Buea, Cameroon
}

Raphael A. Abong

School of Health Sciences, Meridian Global

University, Buea, Cameroon
Carine K. Nfor

School of Health and Human Services, Saint

Monica University, Buea, Cameroon

Kenric B. Ware

South University School of Pharmacy, South Carolina, USA
Elvis A. Akomoneh

Meridian Global Education and Research Foundation, Buea, Cameroon

\section{Sylvester N. Atanga}

School of Health and Human Services, Saint Monica University, Buea, Cameroon

\section{ABSTRACT}

Introduction: Despite a global progress recorded in reproductive health education, adolescent pregnancy remains high especially in low-income countries including Cameroon. This study assessed pregnancy outcomes and associated risk factors among adolescents in Buea Health District, Southwest Region, Cameroon.

Methodology: A community-based descriptive crosssectional research design was used in data collection from March to June 2017. Retrospective data from January 2014 to December 2016 from the maternity department of four randomly selected health facilities in Buea Health District were collected. Moreover, using structured questionnaire, data were collected from post-menarcheal adolescents living within the health area. Data collected were analyzed using SPSS Statistics 20.0 and were considered significant at $\mathrm{P} \leq$ 0.05 .

Results: The proportion of adolescent births was $16.2 \%(652 / 4031)$. Low birth weight infants $(\mathrm{OR}=$ 1.6, $95 \% \mathrm{CI}: 1.28-2.02)$ and preterm babies $(\mathrm{OR}=$ $2.4,95 \%$ CI:1.86-3.32) were the adverse fetal outcomes attributed to adolescent pregnancies. Adverse maternal outcomes were higher in adult women than adolescent mothers $(\mathrm{P}<0.05)$. Unemployment $(\mathrm{OR}=2.1,95 \%$ CI:0.99-4.32), poor financial status $(\mathrm{OR}=12.1,95 \% \mathrm{CI}: 2.60-55.97)$, peer pressure ( $\mathrm{OR}=1.3, \mathrm{CI}: 0.86-2.39)$, lacked knowledge of reproductive health $(\mathrm{OR}=1.79,95 \% \mathrm{CI}: 1.04-2.98)$ and poor use of contraceptives $(\mathrm{OR}=2.24,95 \% \mathrm{CI}$ : 1.30-3.59) were associated with adolescent pregnancy.

Conclusion: Adolescent pregnancies are frequent in Buea Health District with higher probabilities of developing adverse fetal outcomes than adult pregnancies. Unemployment, poor financial status and lack of knowledge on reproductive health were associated with the high prevalence of adolescent pregnancy thus indicating a need for approaches that promote adolescent's involvement in family planning activities.

Keywords: Adolescents, Pregnancy Outcome, Knowledge, Risk Factors 


\section{INTRODUCTION}

Adolescent or teenage pregnancy is pregnancy that occurs in girls aged $10-19$ years (1). Despite a significant progress recorded in reproductive health education, adolescent pregnancy continues to be an increasing public health concern worldwide. Statistics from WHO revealed that in 2014, approximately 16 million adolescents aged 15 to 19 become pregnant each year, constituting $11 \%$ of all births worldwide with $90 \%$ of these births occurring in low income countries (1)(2). Averagely, 143 births per 1000 females aged 10-19 years occur in sub-Sahara Africa (3). In Cameroon, adolescent girls contribute to nearly $14 \%$ of all childbirths in the country with $2.83 \%$ of these being girls under the age of 16 (4). Many of these young women undergo unsafe abortions, where risks of dying from pregnancy-related causes are very high (5).

Although a declined rate of adolescent fertility has been recorded globally (1)(6) adolescent pregnancies, births, and their associated negative effects remain serious problems in many developing countries. Complications during pregnancy and childbirth are consistently the second cause of death for girls aged 15 to 19 years (7). Moreover, babies of adolescent mothers are more likely to be stillborn with low Apgar score, die early, or with long term health challenges. Adolescents who become pregnant while schooling are at risk of abridged education, and thus limited career prospects $(8)(9)$. To complement health education, there is a need for routine assessment of adolescent predisposing factors.

Many physical, psychological, environmental and socio-cultural factors such as peer pressure, lack of knowledge of reproductive health, have been associated to adolescent pregnancy especially in developing countries as this is a period of transition (10). Access to preventive measures such as contraceptives, sexual health information and family planning services remain scarcely available to adolescents in many societies. Even when contraceptives are widely accessible, adolescents are less likely to use them in comparison to adults. Determinants of sexual and reproductive health include several factors beyond available health care services, as socioeconomic variables also have significant effects on outcomes. Adolescent pregnancy is not just a health concern; it is also a socio-economic development issue. Becoming a young mother leads to a higher risk of a life in poverty, partly due to loss of educational and employment opportunities (11) (12). Even today, many adolescent girls are married off at an early age and therefore shoulder societal pressures to become pregnant early in life. Yet in recent years, due to education and cultural changes, many girls now delay marriage until they get older. As a result, adolescents today will be more likely to have sex with multiple partners before they get married, and it is recognized that premarital pregnancy rates are increasing worldwide, even in low- to middle-income countries where typically more conservative attitudes towards extramarital sex are observed (13).

Cameroon is one of the countries in Sub-Saharan Africa where adolescent pregnancies are recognized as a public health challenge. It has been observed that childbearing begins early in Cameroon, with $>12 \%$ of adolescent girls either pregnant or already having one child before their $18^{\text {th }}$ birth day (4) (14). Moreover, adolescent girls who give birth have a much higher risk of dying from maternal causes compared to women in their 20 s and 30 s. These risks increase greatly as maternal age decreases, with adolescents under 16 facing four times the risk of maternal death than women over 20 (4) (15). Evidence shows that Cameroonian adolescents follow a worldwide trend in having their sexual intercourse debut at an early age, the mean age for first sexual experience being at 15 years. Additionally, many adolescents are engaged in unprotected sexual practices, combined with having multiple partners. This puts them at greater risk of unwanted pregnancies and leads them to having unsafe abortions (16). In Cameroon, induced abortion is restricted by law, thus majority of abortions are performed under unsafe conditions. Numbers from year 2000 and 2003 showed an estimated 20-29 unsafe abortions per 1000 women aged $15-49$ years in Cameroon (4).

Due to the risk associated with high prevalence of early sexual behavior, low contraceptive use, and many early pregnancies, adolescents in Cameroon constitute an important target group for sexual and reproductive health programs (4) (17). To prevent early age pregnancies, it is important to make sure that adolescents have the means to make informed and healthy choices concerning their sexual and reproductive health. Sexual health education, access to contraceptives and adolescent-oriented health care services are important elements in preventing early 
pregnancies. Nevertheless, in many low and middleincome countries, Cameroon included, health facilities often fail to provide adolescents with sexual health information, counseling or adolescent-friendly health services (18). This can be due to lack of knowledge by health professionals to communicate with this age group to meet them at their level. We herein assess pregnancy outcomes and risk factors among adolescents in Buea Health District, Southwest Region of Cameroon.

\section{METHODOLOGY}

\section{Study Area}

This study was conducted in Buea Health District (BHD), Southwest Region of Cameroon. BHD is one among the 4 and 18 districts of the Fako division and Southwest Region, respectively with an estimated human population of 147,842 inhabitants (19). The district is situated at latitude $4.15^{\circ}$ North longitude $9.24^{\circ}$ East, and $15 \mathrm{~km}$ from the Atlantic Ocean. It covers a total surface area of 870 square $\mathrm{km}$ (20). There are 67 communities in the district, some of which are rural while others are urban. Indigenes of the district are of the Bakweri tribe and part of the Bantu ethnic group (20). However, the area attracts individuals from other tribes and ethnic groups including the Semi-Bantu and Foulbe from all over the country for farming, business and studies. The district also houses Mt. Cameroon, the highest mountain in west and Central Africa that serves as a touristic site for most foreigners visiting Cameroon (21).

\section{Study Population and Design}

The study was conducted in four health facilities within BHD namely Buea Regional Hospital (BRH), the Molyko Health Center, the Muea Health Center, and the Bolifamba Health Center between March and June 2017. A descriptive cross-sectional design was used in this study. Retrospective data from January 2014 to December 2016 were exploited from registers of labor and delivery report of the maternity department of each of the selected health facility. Using a pre-tested structured questionnaire, data were also collected from post-menarcheal adolescents living within the health facilities during the study period.

\section{Sample Size and Sampling Technique}

The minimum sample size for cross-sectional study was determined using the Olorunfemi Amoran approach. $^{22}$ at $5 \%$ error margin and $95 \% \mathrm{CL}$ thus:

$$
n=\frac{Z \alpha^{2} p q}{d^{2}}
$$

Where $\mathrm{n}=$ sample size, $\mathrm{Z}_{\alpha}=$ standard normal deviate, set at 1.96 (for $95 \%$ confidence level), $\mathrm{d}=$ desired degree of accuracy 5\% (0.05) and $p=$ the estimate of our target population having teenage pregnancy = $29.1 \%{ }^{14}$ A $10 \%$ adjustment of rates of invalid and non-responses gives a minimum sample size of 321 respondents. A total of 423 participants were enrolled for the study.

Buea Health District has a total of 31 health facilities [public and private $(25$ health centers and 6 hospitals)]. located in seven health areas namely Bokwango, Bova, Buea Road, Buea Town, Molyko, Muea and Tole, with Molyko and Buea Road having the highest numbers of health facilities and total population, respectively. ${ }^{19}$ Simple random sampling technique was used to select three health areas and four health facilities carrying out maternity services.

\section{Survey and data collection}

Retrospective Data: Retrospective data from registers of labor and delivery at the maternity department of each of the selected health facility was exploited. Information of all registered pregnancies (both adolescent and adult pregnancies) such as age, marital status, gestation period, type of delivery, birth complications and birth outcome recorded from January 2014- December 2016 were collected. Any data entering without age of participant was discarded and was not considered for analysis.

Questionnaire Design and Administration: The descriptive cross-sectional study was also conducted in the four selected health facilities using structured questionnaire. The questionnaire was designed to obtain information from post-menarchal adolescents on knowledge of reproductive health as well as factors that influence early sexual practices among adolescents. The first part of the questionnaire was structured to contain aspect of basic demographics including age group, marital status, level of education, occupation, family composition, family financial situation and age at first intercourse. The second part 
was structured to capture information regarding their awareness about reproductive health such as knowledge on sexuality, the menstrual cycle as well as contraceptives.

\section{Data Collection Procedure}

In addition to the researcher, four skilled research assistants (interviewers) were recruited and trained to administer the structured questionnaire. They were trained on the tools to be used, purpose of the study and how to approach respondents and obtain consent. Data were collected by face-to-face interviews of adolescents who must have started menstruation and living within the four selected health areas. A multistage sampling technique was used in data collection. From each of the four health areas selected, four communities were randomly chosen. In each randomly selected community, households with adolescents were visited. Research assistants were dispatch to various areas in pairs. Prior to data collection, the purpose of the study was carefully explained to the respondent and her verbal/signed informed consent obtained before the questionnaire was administered. Completeness of the questionnaires was ensured in the field by ensuring that all questions administered and answered were properly entered in the allotted space provided in the questionnaire.

\section{Data Entry and Analysis}

Data were double entered in Microsoft Excel and analyzed using SPSS Statistics 20.0 (IBM Corp, Atlanta, GA, USA). Descriptive statistics was carried out to measure percentages, averages, and relative frequencies of the variables. Relationships between quantitative variables associated with fetal and maternal outcomes as well as individual factors influencing the prevalence of adolescent pregnancy were assessed using the Pearson's Chi-Squared $\left(\chi^{2}\right)$ test at $95 \%$ confidence interval $(\mathrm{CI})$. The variables that were significantly associated to pregnancy outcomes and risk factors of adolescent pregnancy were analyzed using logistic regression, and only variables with a significance threshold of less than 0.05 were included in the final model. Results were reported as adjusted odd ratios (OR) together with their confidence intervals. Statistical level of significance was set at $\mathrm{P} \leq 0.05$.

\section{Ethical Considerations}

Ethical clearance was obtained from the Institutional Review Board of Saint Monica University. Administrative authorizations were sought from the South West Regional Delegation of Public Health as well as the Buea District Health Service (R11/MINSANTE/SWR/RDPH/PS/40/709). Only individuals who volunteered to participate by signing a written informed consent, after adequate sensitization on the project objectives, risks and possible benefits were enrolled.

\section{RESULTS}

A total of 4,031 birth records were collected retrospectively from registers of labor and delivery of the four (4) selected health facilities within Buea Health District from 2014-2016. The age distribution of adolescent pregnancy ranged from 13 to 19 years old with a mean age distribution of $18.62 \pm 1.47 \mathrm{SD}$. The proportion of adolescent births in the study population was $16.2 \% \quad(652 / 4031)$. Of the 423 adolescents who participated in the survey, majority were middle adolescents aged 16-19 years $(92.0 \%)$, of secondary level of education $(65.7 \%)$, students $(71.2 \%)$, of protestant religious affiliation (44.22\%), from semi-urban communities (40.4\%), with family composition consisting of both parents $(56.7 \%)$ and having an average family financial status (70.7\%), (Figure1). The prevalence of adolescent pregnancy was $34.8 \%$ (147/423). 


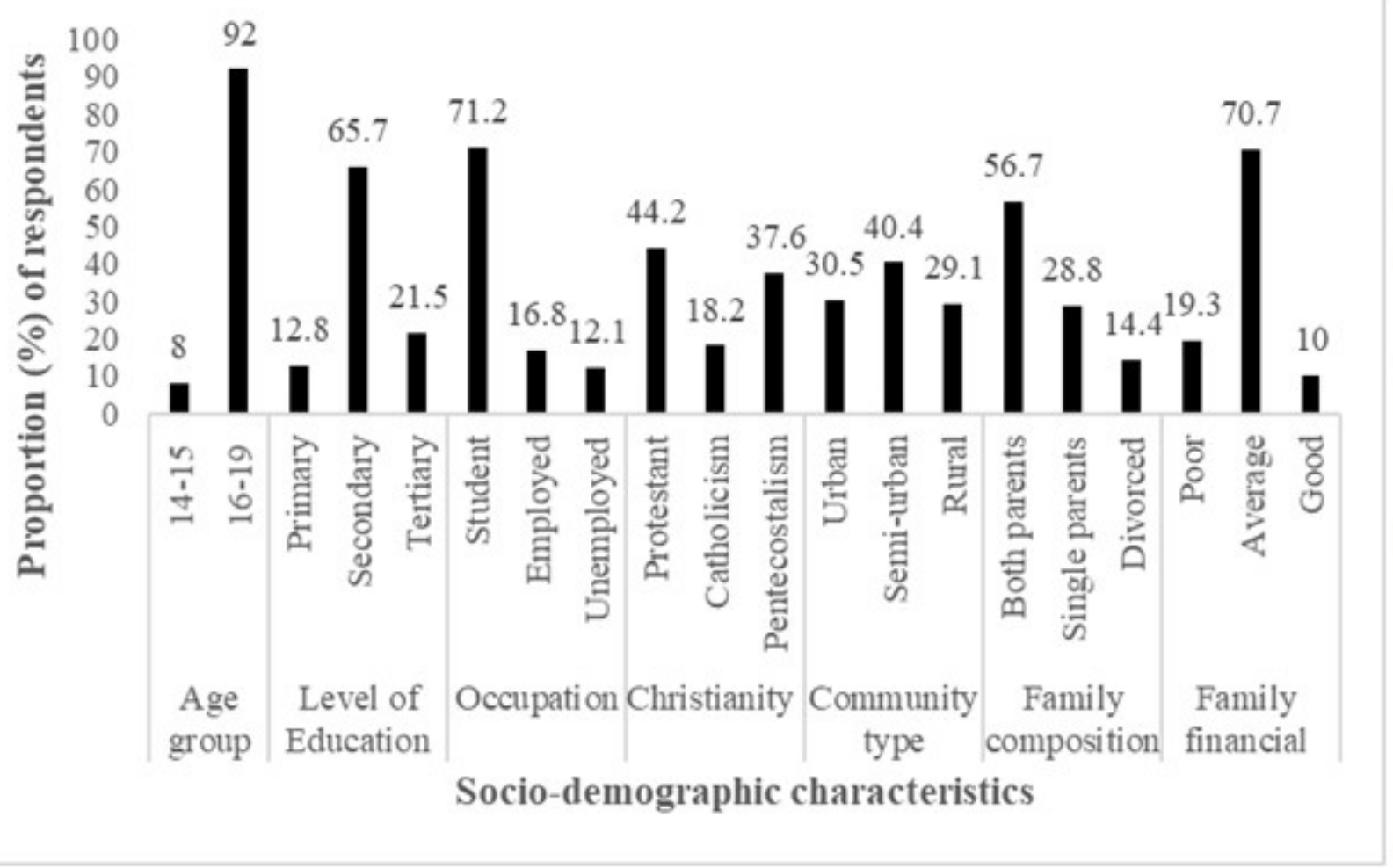

Figure 1 Socio-demographic characteristics of surveyed data

\section{Socio-demographics Characteristics of Adolescent Pregnancy from 2014-2016 Data}

Table 1 shows the distribution of adolescent pregnancy and socio-demographic variables. It was observed that adolescent pregnancy was 4.0 times $(\mathrm{OR}=4.0,95 \% \mathrm{CI}: 3.39-4.82, \mathrm{P}<0.001)$ higher among unmarried $(60.3 \%$ (383)] compared to married adolescents [39.7\%(252)]. Furthermore, adolescent pregnancy was 2.9 times and 1.8 times more likely to be higher in birth records from Bolifamba health center [28.5\% (103)] and among participants living in rural communities [20.8\% (229)] respectively than their counterparts. For the three years cohort study, 2015 [(17.1\%) 251] recorded the highest proportion of adolescent pregnancy [24.0\% (194/809)], though not statistically significant $(\mathrm{P}=0.452)$.

Table 1 Comparison of Socio-demographic Variables among Adolescents ( $\leq 19$ years) and Adult Group ( $\geq 20$ years) from 2014-2016 Data

\begin{tabular}{|c|c|c|c|c|}
\hline Variables & Adolescents [n (\%)] & Adults $[n(\%)]$ & OR $(95 \% \mathrm{CI})$ & P-value \\
\hline Number of Deliveries & $652(16.2)$ & $3379(83.8)$ & & \\
\hline \multicolumn{5}{|l|}{ Marital Status } \\
\hline Unmarried & $383 / 652(60.3)$ & $891 / 3379(27.3)$ & \multirow[t]{2}{*}{$4.0(3.39-4.82)$} & \multirow[t]{2}{*}{$<0.001$} \\
\hline Married & $252 / 652(39.7)$ & $2368 / 3379(72.7)$ & & \\
\hline \multicolumn{5}{|l|}{ Health Facility } \\
\hline Buea Regional Hospital & $314 / 2622(12.0)$ & $2308 / 2622(88.0)$ & \multirow[t]{4}{*}{$2.9(2.26-3.78)$} & \multirow[t]{4}{*}{$<0.001$} \\
\hline Molyko Integrated Health Centre & $23 / 100(23.0)$ & $77 / 100(77.0)$ & & \\
\hline Muea Medical Health Centre & $212 / 947(22.4)$ & 735/947(77.6) & & \\
\hline Bolifamba Health Centre & $103 / 362(28.5)$ & $259 / 365(71.5)$ & & \\
\hline \multicolumn{5}{|l|}{ Community Type } \\
\hline Rural & 229/1101(20.8) & $872 / 1101(79.2)$ & \multirow[t]{3}{*}{$1.8(1.51-2.23)$} & \multirow[t]{3}{*}{$<0.001$} \\
\hline Semi-urban & 166/912(18.2) & $746 / 912(81.8)$ & & \\
\hline Urban & 250/1994(12.5) & $1744 / 1994(87.5)$ & & \\
\hline Year & & & & \\
\hline
\end{tabular}


International Journal of Trend in Scientific Research and Development (IJTSRD) ISSN: 2456-6470

\begin{tabular}{|c|c|c|c|}
\hline 2014 & $204 / 1333(15.3)$ & $1129 / 1333(84.7)$ & \multirow[t]{3}{*}{0.452} \\
\hline 2015 & $251 / 1468(17.1)$ & $1217 / 1468(82.9)$ & \\
\hline 2016 & $197 / 1230(16.0)$ & $197 / 1230(84.0)$ & \\
\hline
\end{tabular}

$\mathrm{OR}=$ odd ratio, $\mathrm{CI}=$ confidence interval, Adolescents defined as mothers $\leq 19$ years, Adults defined as mothers $\geq 20$ years.

Category not shown: missing

\section{Comparison of Fetal and Maternal Outcomes}

Adolescent mothers were more likely to have low birth weight infants $(\mathrm{OR}=1.6,95 \% \mathrm{CI}: 1.28-2.02, \mathrm{P}<0.03)$, preterm babies $(\mathrm{OR}=2.4,95 \% \mathrm{CI}: 1.86-3.32, \mathrm{P}<0.001)$ than adult women. Moreover, post-term babies $(\mathrm{OR}=$ $2.4,95 \% \mathrm{CI}: 1.86-3.32, \mathrm{P}<0.001)$ and neonatal death were higher in adult mothers than adolescent mothers $(\mathrm{P}>0.05)$, (Table 2).

The rates of instrumental deliveries, perineal tears and episiotomy were higher among adolescent mothers than adult mothers though not statistically significant $(\mathrm{P}>0.05)$. The rates of caesarian sections were 2.1 times $(\mathrm{OR}=2.1,95 \% \mathrm{CI}: 1.58-2.81, \mathrm{P}=0.004)$ greater in adult mothers than adolescent mothers. Furthermore, though there were no significant differences between preeclampsia, dystocia, hemorrhage and uterine rupture in the two groups $(\mathrm{P}>0.05)$, they were generally higher in adult mothers than adolescent mothers.

Table 2 Comparison of Fetal and Maternal Outcomes among Adolescents ( $\leq 19$ years) and Adult $(\geq 20$ years) Group

\begin{tabular}{|c|c|c|c|c|}
\hline Outcome & Adolescents [n (\%)] & Adults [n (\%)] & OR $(95 \% \mathrm{CI})$ & P-value \\
\hline Birth weight & O & 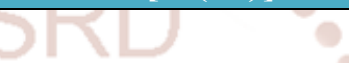 & $\beta$ & \\
\hline low $(<2.5 \mathrm{~kg})$ & $112 / 635(17.6)$ & $386 / 3285(11.8)$ & $1.6(1.28-2.02)$ & 0.001 \\
\hline Normal $(>2.5 \mathrm{~kg})$ & $523 / 635(82.4)$ & $2899 / 3285(88.2)$ & \% & \\
\hline Average $($ mean \pm SD) & $635(3.00 \pm 0.51)$ & $3285(3.17 \pm 0.58)$ & $1.6(1.40-1.86)$ & 0.002 \\
\hline Neonatal death & $11 / 576(1.9)$ & $91 / 2917(3.1)$ & 0 & 0.115 \\
\hline Gestation at delivery & O & & 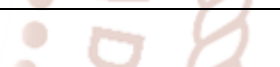 & \\
\hline Preterm $(<37$ weeks $)$ & $159 / 625(24.5)$ & $531 / 3262(16.3)$ & $2.4(1.86-3.32)$ & 0.001 \\
\hline Postdates ( $>40$ weeks) & $81 / 625(13.0)$ & $671 / 3262(20.6)$ & & \\
\hline Average (mean \pm SD) & $625(37.91 \pm 3.09)$ & $3262(38.7 \pm 2.88)$ & $1.1(1.06-1.12)$ & 0.003 \\
\hline Delivery type & 8 & 20 & 2 & \\
\hline Caesarian section & $56 / 648(8.6)$ & $556 / 3345(16.6)$ & $2.1(1.58-2.81)$ & 0.004 \\
\hline Instrumental & $5 / 648(0.8)$ & $31 / 3345(0.9)$ & 3 & 0.805 \\
\hline Birth complications & & 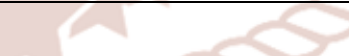 & & \\
\hline Dystocia & $9 / 618(1.5)$ & $51 / 3075(1.7)$ & & 0.717 \\
\hline Hemorrhage & $5 / 609(0.8)$ & $39 / 3029(1.3)$ & & 0.338 \\
\hline Preeclampsia & $1 / 618(0.2)$ & $21 / 3075(0.7)$ & & 0.525 \\
\hline Perineal tear & $78 / 618(12.6)$ & $353 / 3075(11.5)$ & & 0.420 \\
\hline Uterine rupture & $0 / 618(0)$ & $4 / 3075(0.1)$ & & 0.370 \\
\hline Episiotomy & $3 / 618(0.6)$ & $5 / 3075(0.2)$ & & 0.295 \\
\hline Maternal death & $0 / 576(0.0)$ & $10 / 2917(0.3)$ & & 0.159 \\
\hline
\end{tabular}

$\mathrm{OR}=$ odd ratio, $\mathrm{CI}=$ confidence interval

Adolescents defined as mothers $\leq 19$ years.

Adults defined as mothers $\geq 20$ years.

Category not shown: missing 
International Journal of Trend in Scientific Research and Development (IJTSRD) ISSN: 2456-6470

\section{Individual Factors Influencing the Prevalence of Adolescent Pregnancy}

The risk factors associated with adolescent pregnancy in the study population were occupation $(\mathrm{P}=0.006)$, family financial status $(\mathrm{P}<0.001)$, age at menarche $(\mathrm{P}=0.002)$, peer pressure $(\mathrm{P}=0.037)$, knowledge on reproductive health $(\mathrm{P}=0.010)$ and the use of contraceptives $(\mathrm{P}<0.001)$, (Table 3$)$.

Adolescents from a poor financial background ( $\mathrm{OR}=12.1,95 \% \mathrm{CI}$ : 2.60-55.97) were more likely to be pregnant. Adolescents who started menstruation at the age younger than 13 years $(\mathrm{OR}=1.9$, CI: 1.16-3.18) more likely to be pregnant followed by adolescents who were under peer pressure (OR=1.3, CI: 0.86-2.39). Adolescents who lacked knowledge of reproductive health and dislike using contraceptives were 1.8 times $(\mathrm{OR}=1.79,95 \% \mathrm{CI}: 1.04-2.98)$ and 2.2 times $(\mathrm{OR}=2.24,95 \% \mathrm{CI}: 1.30-3.59)$, respectively more likely to be pregnant than their counterparts.

Table 3 Individual Factors Associated with Adolescents Pregnancy in the Study Population

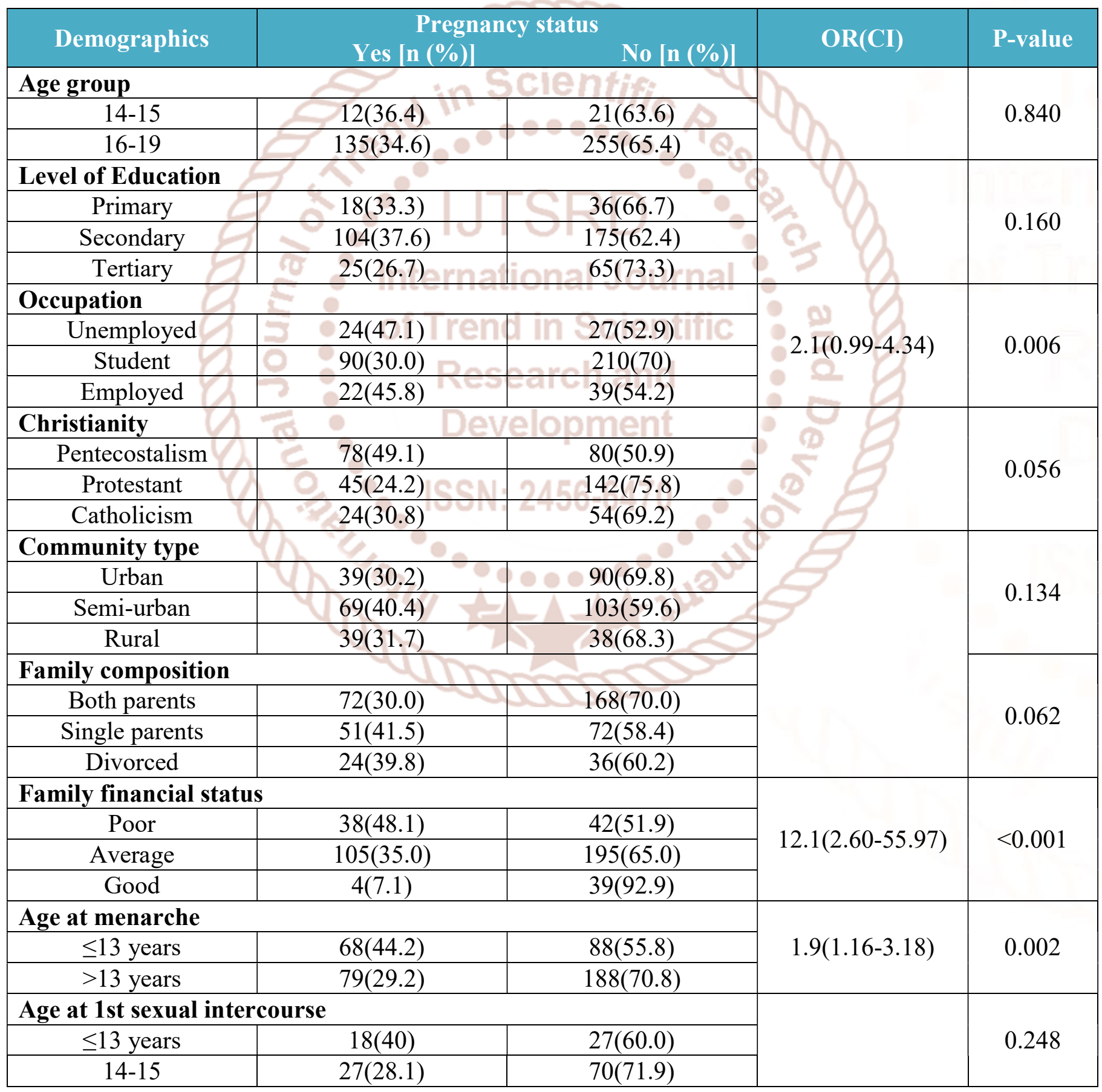


International Journal of Trend in Scientific Research and Development (IJTSRD) ISSN: 2456-6470

\begin{tabular}{|c|c|c|c|c|}
\hline $16-19$ & $102(36.4)$ & $176(63.4)$ & & \\
\hline \multicolumn{3}{|l|}{ Peer pressure } & \multirow{3}{*}{$1.3(0.86-2.39)$} & \multirow{3}{*}{0.037} \\
\hline Yes & $60(39.2)$ & $142(60.8)$ & & \\
\hline No & $87(29.9)$ & $134(70.1)$ & & \\
\hline \multicolumn{3}{|c|}{ Knowledge on reproductive health } & \multirow{3}{*}{$1.8(1.04-2.98)$} & \multirow{3}{*}{0.010} \\
\hline Poor Knowledge & $104(39.3)$ & $163(60.7)$ & & \\
\hline Good knowledge & $43(26.9)$ & $113(73.1)$ & & \\
\hline \multicolumn{3}{|l|}{ Use contraceptives } & \multirow{3}{*}{$2.2(1.30-3.59)$} & \multirow{3}{*}{$<0.001$} \\
\hline dislike contraceptive & $93(44.3)$ & $117(55.7)$ & & \\
\hline frequent usage & $54(26.9)$ & $147(73.1)$ & & \\
\hline
\end{tabular}

$\mathrm{OR}=$ odd ratio, $\mathrm{CI}=$ confidence interval

Adolescents defined as mothers $\leq 19$ years.

Adults defined as mothers $\geq 20$ years.

Category not shown: missing

\section{DISCUSSION}

Despite a global progress recorded in reproductive health education, adolescent pregnancy continues to be a problem especially in low and middle-income countries (LMIC), as well as in high-income countries (HIC). Adolescent pregnancy continues to be a social, economic and cultural problem especially tin developing countries due to its continuing rise that has an adverse impact to both adolescent and the community (23). The present study assessed the pregnancy outcomes and risk factors among adolescents in Buea Health District. A study as this will identify the areas to be emphasized in the health promotion practice related to adolescent pregnancy.

The proportion of adolescent births in this study was $16.2 \%$. This proportion was higher among unmarried adolescents living in rural communities. This finding is however higher when compared to previous studies in the district ${ }^{14}$ and in Vietnam ${ }^{8}$ and lower when compared to findings in other African countries and beyond (22) (24) (25). This high proportion recorded especially in rural communities could be attributed to low literacy regarding reproductive health couple with high level of unemployment which are important contributing factors to adolescent pregnancy. Our finding further revealed that the prevalence of sampled adolescent pregnancy was $34.8 \%$. This result is higher when compared to previous studies in Cameroon (14) (27). These findings therefore suggest that, despite several campaigns against adolescent pregnancy in the developing countries, the incidence of adolescent pregnancy has not decreased. Comparatively, adolescent pregnancy in developing countries has been reported to be worse than in developed countries (28). This is worrying, particularly the fact that it suggests that there is little progress made in reducing adolescent pregnancy over the past few decades, despite its importance as highlighted in the Millennium Development Goals (MDG) and its association to maternal mortality and morbidity rates (28). Innovative approaches to promote the involvement of the adolescents in family planning activities are therefore urgently needed.

Several studies have reported that adolescents are exposed to adverse fetal outcomes such as low birth weight, neonatal death and low Apgar score. This study revealed that pregnant adolescents had higher rates of premature babies and low birth weight infants than adult mothers. This corroborates other studies in Cameroon (4) (14). However, the rates of post-term and neonatal deaths were lower in adolescent mothers than adult women (14). Of the maternal outcomes considered, we found more adverse maternal outcomes in adult mothers than adolescent mothers. Adolescent mothers were more likely to have a vaginal delivery and had a lower risk of caesarean section than adult mothers, a situation which contradicts those reported in literature on the subject (14) (15). However, this result is consistence with some previous studies (9) (28) and thus should be examined carefully. Previously, studies had suggested that adolescents are at an increased risk of caesarean section and obstructed labor due to biological immaturity of the adolescent pelvis bone which causes cephalo-pelvic disproportion (9). This was however not confirmed in this study probably due to small sample size studied. The rates of dystocia, hemorrhage, preeclampsia and uterine rupture were 
higher in adult mothers than adolescent mothers though not statistically significant.

It was also observed in this study that the rate of perineal tears and episiotomy were higher among adolescent mothers than adult women. This result corroborates with previous studies in Turkey (29). It has been reported that adolescent mothers were more likely to die from pregnancy and delivery complications (30) (31). However, we did not record any maternal deaths among adolescent mothers in this study.

This study also exploited risk factors of adolescent pregnancy. Results of this study showed that $>60 \%$ of respondents interviewed had engaged in sexual intercourse. The age at first sexual intercourse ranged from 12 to 19 years with a mean of $16.23 \pm 1.83$ SD. The most active age for sexual activities was 17 years. It was observed that sexual activities increased gradually with age from adolescents of 12 years to 17 years and then decreased steadily to adolescents of 19 years old. The mean age for sexual activities observed in this study was lower compared to other studies in Africa (27) (32). This might probably be a contributing factor to the high prevalence of adolescent pregnancy observed in the study population. Result of this study revealed that poverty is a risk factor of adolescent pregnancy. Adolescents who were unemployed and from a poor family background were at risk of getting pregnant, a situation very much like those reported in literature on the subject (33). Respondents with poor family background were more prone to early sexual practices than those from average or good family background. Similar studies confirm this result (34) (35), reaffirming the fact that poverty is a cause and a consequence of early child bearing. The younger people suffer from poverty, the more the chances are for them to engage in risky sexual behavior. Findings further reveal that early sexual practices were higher among respondents living in rural communities than respondents living in urban communities. This might be due to poor knowledge on sexuality observed in this group. Beshir et al (36) confirms this results in a similar study conducted in Sudan suggesting that sexual debut is a risk factor to adolescent pregnancy. Peer pressure and lack of financial support were reported by majority of respondents as contributing factor to early sexual intercourse. This result is comparable to finding of Marston et al (37) which showed that peer pressure is a risk factor of adolescent pregnancy. Moreover, adolescents who lacked knowledge of reproductive health and disliked using contraceptives were 1.8 times and 2.2 time respectively more likely to be pregnant than their counterparts.

\section{CONCLUSION}

The proportion of adolescent births in this study was higher compared to previous studies. Adverse maternal outcomes were higher in adult women than adolescent mothers. The adverse fetal outcomes associated with adolescent pregnancies were low birth weight and preterm babies. Unemployment, poverty peer pressure, lack of knowledge on reproductive health and poor use of contraceptives were among the risk factors associated with adolescent pregnancy.

\section{Acknowledgments}

We thank the participants from the communities in Buea Health District who made this study possible by giving their consent. We equally thank Meridian Global Education and Research Foundation (MGERF), Cameroon for financial support.

\section{Author contributions}

Conceived and designed the experiments: MUA, CKN and SNA; data acquisition. CKN, EAA and RAA; performed statistical analysis. MUA and KBW, drafted the manuscript and made critical revision of the manuscript for key intellectual content. MUA, CKN, KBW, SNA, EAA and RAA. All authors have agreed to authorship and order of authorship for this manuscript.

\section{Disclosure}

The authors declare that they have no competing interests.

\section{References}

1. World Health Organization. Adolescent pregnancy. WHO factsheet. 2014. Available at: http://www.who.int/mediacentre/factsheets/fs364/ en/.

2. Christiansen CS, Gibbs S, Chandra-Mouli V. Preventing early pregnancy and pregnancy-related mortality and morbidity in adolescents in developing countries: the place of interventions in the prepregnancy period. J Pregnancy. 2013; 2013:257546. doi: 10.1155/2013/257546. 
International Journal of Trend in Scientific Research and Development (IJTSRD) ISSN: 2456-6470

3. World Health Organization: Adolescent pregnancy: Issues in adolescent health and development. .2004 . Available at: http://apps.who.int/iris/bitstream/10665/42903/1/9 241591455_eng.pdf/. Accessed June 8, 2017.

4. Tebeu PM, Kemfang JD, Sandjong DI, et al. Geographic distribution of childbirth among adolescents in Cameroon from 2003 to 2005. Int J Gynaecol Obstet 2010. Doi:10.1155/2010/805165.

5. World Health Organization. Preventing early pregnancy and poor reproductive outcomes among adolescents in developing countries.2006.Available

at: http://www.who.int/immunization/hpv/target/prev enting_early_pregnancy_and_poor_reproductive_ outcomes_who_2006.pdf/

6. McCall SJ, Bhattadharya S, Okpo E \& Macfarlane $\mathrm{GH}$. Evaluating the social determinants of teenage pregnancy: A temporal analysis using a UK obstetric database from 1950 to 2010. J Epidemiol Community Health 2015; 69: 49-54.

7. Girls not Bridges. Health: Child marriage has devastating consequences on a girl's health. Available https://www.girlsnotbrides.org/themes/health. Accessed July 10, 2017.

8. Nguyen H, Shiu C \& Naomi Farber N. Prevalence and factors associated with teen pregnancy in Vietnam: results from two national surveys. Societies 2016; 6: 17. DOI:10.3390/soc6020017

9. Ganchimeg E, Ota N, Morisaki M, et al. Pregnancy and childbirth outcomes among adolescent mothers: a World Health Organization multi-country study. BJOG 2014;121(1):40.

10. AbdulKarim SM. Adolescent health and health care in the Arab Gulf countries: Today's needs and tomorrow's challenges. Int J Pediatr Adolesc Med 2017; 4(1): 1-8.DOI: org/10.1016/j.jpam.2016.12.006

11. Chandra-Mouli, Venkatraman \& Alma VC. Adolescent pregnancy: a global perspective. training course in sexual and reproductive health research. Geneva: WHO; 2011

12. United Nations Population Fund. Adolescent pregnancy: a review of the evidence. New York, NY: UNFPA, 2013.

13. Kirby DB, Laris BA, Lori AR. Sex and HIV education programs: their impact on sexual behaviors of young people throughout the world. J Adolesc Health 2007. Doi: 10.1016/j.jadohealth.

14. Egbe TO, Omeichu A, Halle-Ekane GE, et al. Prevalence and outcome of teenage hospital births at the Buea health district, South West Region, Cameroon. Reprod Health 2015; 12:18. DOI: 10.1186/s 12978-015-0109-5.

15. Kongnyuy EJ, Nana PN, Fomulu N, et al. Adverse perinatal outcomes of adolescent pregnancies in Cameroon. Matern. Child Health J 2008;12 (2): 149-154. Doi:10.1007/s10995-007-0235-y.

16. Foumane P, Chiabi A, Kamdem C, et al. Sexual activity of adolescent school girls in an urban secondary school in Cameroon. J Reprod Infertil. 2013;14 (2): 85-89.

17. Meekers D, \& Klein M. Understanding gender differences in condom use self-efficacy among youth in urban Cameroon." aids education and prevention. AIDS Educ Prev. 2002; 14 (1): 62-72.

18. Mbizvo MT \& Zaidi S. Addressing critical gaps in achieving universal access to sexual and reproductive health (SRH): the case for improving adolescent SRH, preventing unsafe abortion, and enhancing linkages between SRH and HIV interventions. Int J Gynaecol Obstet 2010; 110 Suppl: S3-6. DOI: 10.1016/j.ijgo.2010.04.001.

19. Ajonina MU, Apinjoh TO, Atanga SN, et al. Practices regarding the use of antimalarial medications among inhabitants of the Buea health district, southwestern Cameroon: implications for malaria treatment policy. JHMN 2015; 45.

20. Nsagha DS, Atashili J, Fon PN, et al. Assessing the risk factors of cholera epidemic in Buea Health District of Cameroon. BMC Pub Health 2015 ; 14, 15(1): 1128. DOI: $10.1186 / \mathrm{s} 12889-015-$ 2485-8.

21. Communes et Villes Unies du Cameroun (CVUC). Buea. Available at :http://cvuc.cm/national/index.php/fr/cartecommunale/region-du-sud/142-association/carteadministrative/sud-ouest/fako/404-buea/ 2014.

22. Olorunfemi EA. A comparative analysis of predictors of teenage pregnancy and its prevention in a rural town in Western Nigeria. Int J Equity Health 2012; 11: 37.

23. Basch CE. Teen pregnancy and the achievement gap among urban minority youth. J Sch Health 
2011; 81(10):614-8. DOI: $10.1111 / \mathrm{j} .1746-$ 1561.2011.00635. x.

24. Tamramat IR, Sahr FB. Teenage pregnancy and implications on child survival amongst mothers attending a clinic in the East-End, Freetown, Sierra Leone. OJPed 2013; 3:294-299. DOI: 10.4236/ojped.2013.34053.

25. Sedgh G, Finer LB, Bankole A, et al. Adolescent pregnancy, birth, and abortion rates across countries: levels and recent trends. J Adolesc Health $2015 \quad 56(2): 223-30 . \quad$ doi: 10.1016/j.jadohealth.2014.09.007.

26. Nkwabong E, Fomulu JN. Outcome of pregnancies among Cameroonian anemic women: a comparative cohort study. J Preg Child Health 2014; 1:117. DOI: $10.4172 / 2376-127 X .1000117$

27. Neal SE, Chandra-Mouli V \& Chou D. 35. Panday, S., Makiwane, M., Ranchod, C. et al. Adolescent first births in East Africa: disaggregating characteristics, trends and determinants. Reprod Health 2015; 12(13):13. DOI: $10.1186 / 1742-4755-12-13$

28. Zeteroglu S, Sahin I, Gol K. Cesarean delivery rates in adolescent pregnancy. Eur $\mathrm{J}$ Contracept Reprod Health Care 2005; 10:119-22.

29. Imir GA, Çetin M, Balta Ö, et al. Perinatal outcomes of adolescent pregnancies at a University Hospital in Turkey. J Turk-Ger Gynecol Assoc. 2008; 9:71-4

30. Blanc AK, Winfrey W, Ross J. New findings for maternal mortality age patterns: aggregated results for 38 countries. PLoS One 2013;16;8(4): e59864. DOI: 10.1371/journal.pone.0059864.
31. Acharya DR, Bhattarai R, Poobalan A, et al. Factors associated with teenage pregnancy in South Asia. HSJ 2010; 4:1-13.

32. Tamire W, Enqueselassie F. Knowledge, attitude, and practice on emergency contraceptives among female university students in Addis Ababa, Ethiopia. Ethiop J Health Dev 2007;21(2):111116.

33. Garwood SK, Lara G, Melissa J. More than poverty - teen pregnancy risk and reports of child abuse reports and neglect. J Adolesc Health 2015; 57(2): $\quad 164-168 . \quad$ DOI: 10.1016/j.jadohealth.2015.05.004

34. Smith CA. Factors associated with early sexual activity among urban adolescents. Social Work 1997;42(4): 334-346.

Teenage pregnancy in South Africa: with a specific focus on school going learners. Pretoria: Child, Youth, Family and Social Development, Human Sciences Research Council; 2009.

36. Beshir GM, Manar EA \& Abdallah OS. Foetal and maternal pregnancy outcomes among teenage and adult mothers at Omdurman Maternity Hospital in Sudan. Khartoum Med J 2013;6(2): 881 - 888.

37. Marston M, Beguy D, Kabiru C \& Cleland J. Predictors of sexual debut among young adolescents in Nairobi's informal settlements. Int Perspect Sex Reprod Health 2013;39(1):22-31. DOI: $10.1363 / 3902213$. 